\title{
The Use of Cellomics to Study Enterocyte Cytoskeletal Proteins in Coeliac Disease Patients
}

\author{
Bashir M. Mohamed \\ Department of Immunology, St. James's Hospital Dublin, Trinity College Dublin, Dublin, Ireland \\ Conleth Feighery \\ Department of Immunology, St. James's Hospital Dublin, Trinity College Dublin, Dublin, Ireland \\ Yvonne Williams \\ Department of Immunology, St. James's Hospital Dublin, Trinity College Dublin, Dublin, Ireland
}

See next page for additional authors

Follow this and additional works at: https://arrow.tudublin.ie/scschbioart

Part of the Medicine and Health Sciences Commons

\section{Recommended Citation}

Mohamed, B., Feighery, C. \& Williams, Y. (2008). The Use of Cellomics to Study Enterocyte Cytoskeletal Proteins in Coeliac Disease Patients. Central European Journal of Biology, vol. 3, pages 258-267. doi:10.2478/s11535-008-0029-2

This Article is brought to you for free and open access by the School of Biological Sciences at ARROW@TU Dublin. It has been accepted for inclusion in Articles by an authorized administrator of ARROW@TU Dublin. For more information, please contact arrow.admin@tudublin.ie, aisling.coyne@tudublin.ie,gerard.connolly@tudublin.ie.

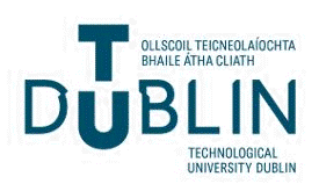




\section{Authors}

Bashir M. Mohamed, Conleth Feighery, Yvonne Williams, Anthony Davies, Dermot Kelleher, Yuri Volkov, Jacinta Kelly, and Mohamed Abuzakouk 


\title{
The use of Cellomics to study enterocyte cytoskeletal proteins in coeliac disease patients
}

\author{
Research Article
}

\begin{abstract}
Bashir M. Mohamed ${ }^{1,2}$, Conleth Feighery ${ }^{1,2 *}$, Yvonne Williams ${ }^{1,2}$, Anthony Davies², Dermot Kelleher?2, Yuri Volkov², Jacinta Kelly³, Mohamed Abuzakouk ${ }^{1,2}$

1 Department of Immunology, St. James's Hospital Dublin, Trinity College Dublin, Ireland

${ }^{2}$ Molecular Medicine Centre Dublin, St. James's Hospital Dublin, Trinity College Dublin, Ireland

${ }^{3}$ Dublin Institute of Technology, Dublin, Ireland
\end{abstract}

Received 19 February 2008; Accepted 5 May 2008

Abstract: Coeliac disease is characterised by inflammation of small intestinal mucosa accompanied by abnormal villous architecture. It is now accepted that some patients with positive coeliac serology tests may have minor mucosal lesions that may not be apparent on routine histopathological analysis. The aim of the study was to perform detailed examination of enterocyte morphology and cytoskeletal structures using a high content analysis technology. Duodenal biopsies from 14 untreated and 10 treated coeliac patients and from 20 non-coeliac controls were examined. Tissue sections from six patients (study group subjects) before and after the development of gluten-sensitive enteropathy were also investigated. Immunohistochemical studies were performed on paraffin-embedded sections using an anti- $\alpha$-tubulin antibody. Significant differences in enterocyte morphology and intracellular cytoskeletal structures were demonstrated in patients with proven coeliac disease and in the study group subjects. These changes were present in study group biopsies before evidence of enteropathy, as assessed by routine microscopy. This is the first study to demonstrate detailed characteristics of enterocyte morphology in coeliac patients using a high content analysis approach. The use of this technology allows a quantitative analysis of enterocyte intracellular structures from routine biopsy material and permits detection of subtle changes that precede the characteristic histological lesion.

Keywords: Coeliac disease • Endomysial antibodies • Enterocytes • Tubulin • High content analysis

(c) Versita Warsaw and Springer-Verlag Berlin Heidelberg.

\section{Introduction}

Coeliac disease is a gluten sensitive enteropathy characterised by inflammation of the small intestinal mucosa, with a range of abnormal villous architecture and crypt hyperplasia features [1-3]. However, several studies have reported only minimal intestinal changes in some patients with positive coeliac serology [4-6]. In a proportion of these patients, detailed histological analysis reveals subtle histological abnormalities such as nuclear disarray, irregular cell shape [7], and an increased number of intraepithelial lymphocytes [4-6] with this increase sometimes confined to the villous tip $[8,9]$. In this clinical setting, the diagnosis of coeliac disease may be missed, unless the patient is regularly monitored for more definitive evidence of gluten sensitive enteropathy.

Cytoskeletal proteins are involved in essentially all structural and dynamic aspects of the living cell, including maintenance of cell shape, movement, replication, apoptosis, differentiation and intracellular signalling [10-12]. Disruption of cytoskeletal structures can severely limit cell function, and if not reversed can adversely affect cell integrity and viability [13-15]. Rearrangement of the cytoskeletal proteins is thought to result in nuclear disarray and alteration of enterocyte 


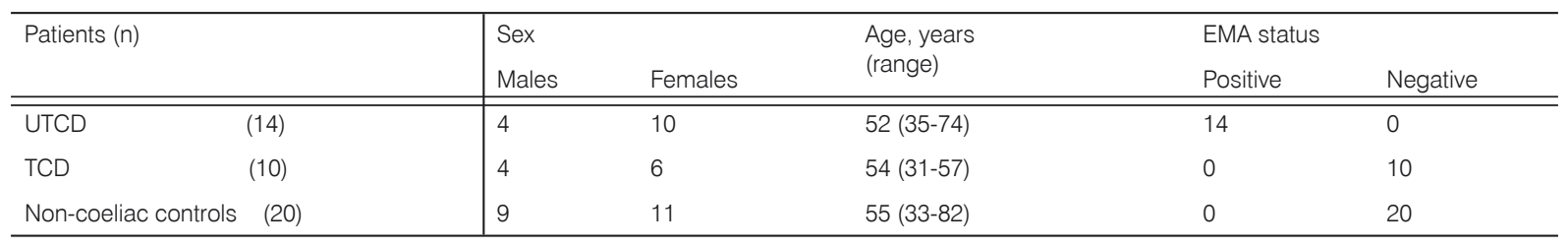

Table 1. Demographic and serologic details of the coeliac groups and non-coeliac controls.

UTCD: untreated coeliac disease; TCD: treated coeliac disease; EMA: endomysial antibody

shape, described features of the coeliac lesion [7]. Many other pathological conditions also demonstrate abnormalities in cytoskeletal proteins, including several cardiovascular disease syndromes, neurodegeneration, cancer, liver cirrhosis, pulmonary fibrosis, and skin diseases [16-20].

The cytoskeleton of eukaryotic cells is composed of three major protein families that form filamentous structures running throughout the cell: microfilaments consisting of different actin isoforms, microtubules made of $\alpha$ - and $\beta$-tubulin, and the intermediate filaments $[10,11,21]$. The actin network has been shown to play an important role in gliadin-induced effects on intestinal epithelial cells, demonstrated by both in vivo and in vitro studies $[22,23]$. Moreover, when coeliac patients on a gluten-free diet were exposed to gliadin, this resulted in disarrangement of intestinal mucosal actin filaments in vivo [24-26]. It has also been demonstrated that Zo-1 expression is reduced in the intestinal mucosa of patients with active coeliac disease and this is associated with a disrupted F-actin organization; these changes were reversed by gluten free diet treatment [27].

In this study, a new technology called high content analysis was used to study details of enterocyte morphology and their tubulin cytoskeletal structures in biopsy tissue from patients with coeliac disease. This system is based on automated extraction of data from cellular images and is proving to be an invaluable tool for the investigation of cytoskeletal networks, allowing study of their complex dynamic changes at a qualitatively new level of detail [28]. Employing the morphology explorer bioapplication tool Cellomics ${ }^{\circledR}$, the system has been used to quantify fluorescent images of the cytoskeleton in the NIH 3T3 cell line [28]. In this study, biopsy tissue from patients with coeliac disease, patients with potential coeliac disease and from disease control subjects was examined. It was hypothesized that changes in cell morphology and cytoskeletal structures might be present in enterocytes from patients with potential coeliac disease, even before the development of a histological lesion on routine microscopy.

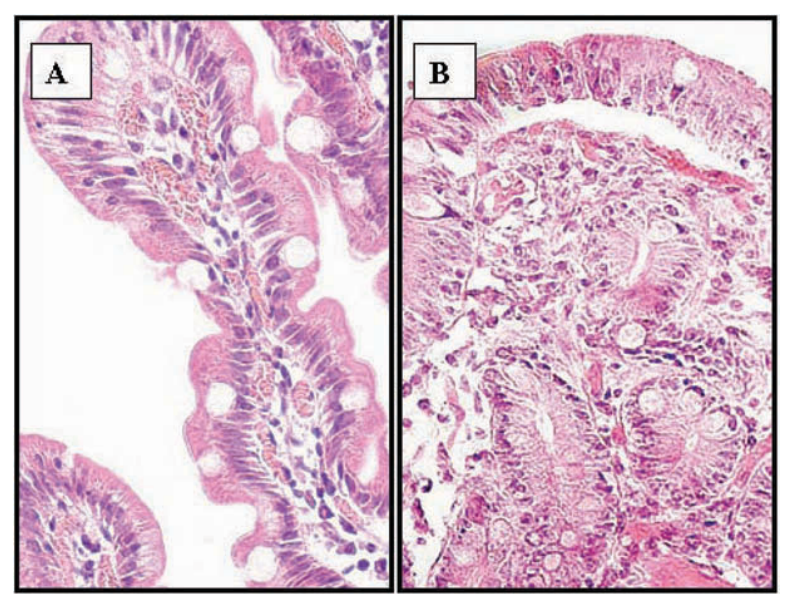

Figure 1. H\&E stained sections demonstrating the routine histological image of the study group subjects with normal duodenal mucosa (A) and after the intestinal lesion was developed (B). (magnification $\times 40$ ).

\section{Experimental Procedures}

\subsection{Patients \\ 2.1.1. Coeliac subjects}

Duodenal biopsies from two patient groups were examined. These included untreated and treated coeliac disease patients. The duodenal histology in 14 patients with untreated disease, all with positive endomysial antibody tests, demonstrated partial villous atrophy and crypt hyperplasia. Ten further coeliac patients, treated with a gluten free diet, were endomysial antibody negative. Demographic and serological details of these two patient groups are given in Table 1.

\subsubsection{Non-coeliac subjects}

The non-coeliac control group comprised 20 subjects who had been investigated because of symptoms of dyspepsia but had normal duodenal mucosa and negative endomysial antibodies (Table 1).

\subsubsection{Study group subjects}

This group comprised six patients with positive endomysial antibody tests who had an apparently normal duodenal mucosa (Figure 1A); these patients presented with symptoms consistent with malabsorption and are 


\begin{tabular}{|c|c|c|c|c|c|c|}
\hline Pt.no & Age (years) & Sex & Symptoms & $E M A$ & $H b$ & Ferritin \\
\hline 1 & 20 & $\mathrm{~F}$ & Anaemia & + & 4.9 & \\
\hline 2 & 49 & $\mathrm{~F}$ & Bloating, dyspepsia, weight loss & + & 13 & 3.9 \\
\hline 3 & 67 & $\mathrm{~F}$ & Bloating, diarrhoea, dyspepsia & + & & 8.7 \\
\hline 4 & 54 & M & Fatigue & + & & \\
\hline 5 & 34 & $\mathrm{~F}$ & Anaemia, diarrhoea, fatigue & + & 11 & 3.9 \\
\hline 6 & 67 & $\mathrm{~F}$ & Weight loss & + & 12 & \\
\hline
\end{tabular}

Table 2. Age, sex, clinical symptoms and laboratory results in the study group subjects.

Ferritin (normal range $=20-300 \mu \mathrm{g} / \mathrm{l}$ ); haemoglobin $(\mathrm{Hb})$ (normal range $=11-18 \mathrm{~g} / \mathrm{dl}$ ) EMA: anti-endomysial antibody

referred to throughout the manuscript as the study group subjects. Demographic, clinical and laboratory features of these patients are presented in Table 2. Based on their normal laboratory findings, none of these patients were considered to have coeliac disease and they were discharged to their primary care physicians. As part of the study, follow up serological and histological evaluation was performed after a mean of 7.5 years (range 5-11 years). This revealed that these patients continued to have positive coeliac serology and all had developed a small intestinal lesion (ranging from partial to total villous atrophy) suggestive of coeliac disease (Figure 1B). The intestinal lesion was scored according to a modified Marsh scale [29]. The original biopsies in the six subjects were subsequently re-evaluated by two blinded histopathologists and again considered to be normal, except in the case of one patient in whom the intra-epithelial lymphocyte count was increased. Additional details concerning these patients have been previously reported [30].

\subsection{Ethics approval}

Ethical approval for this study was granted by the Joint Ethics Committee of St James's Hospital, Dublin, Ireland.

\subsection{Immunofluorescent technique}

$2 \mu \mathrm{m}$-thick duodenal sections from paraffin-embedded blocks were placed on uncoated glass slides and dried overnight at $52^{\circ} \mathrm{C}$. Sections were dewaxed and rehydrated in a series of graded xylene and alcohol solutions and subsequently immersed in phosphatebuffered saline solution (PBS) at $\mathrm{pH}$ 7.4. Sections were then preheated for antigen retrieval in a microwave oven in $0.1 \mathrm{M}$ citrate buffer $\mathrm{pH} 6.0$ for 20 minutes on high power and cooled for 20 minutes at room temperature. After immersing the prepared samples in PBS, the sections were next incubated with anti- $\alpha$-tubulin antibody (clone B-5-1-2, Sigma, St Louis, MO) at 1:100 dilution in antibody buffer $(0.05 \%$ bovine serum albumin and 0.1 sodium azide in PBS) for 60 minutes at $4^{\circ} \mathrm{C}$.
Sections were then incubated with $A$ lexa ${ }^{\circledR}$ (Molecular Probes, Eugene, OR) fluorescent conjugated secondary antibody at 1:500 in dilution buffer for 30 minutes. Cell nuclei were counterstained with $1 \mu \mathrm{M}$ Hoeschst 33258 (Sigma, St Louis, MO). After each antibody application, sections were washed twice in PBS. Sections were then mounted with DAKO fluorescent mounting media (Sigma, St Louis, MO) and kept in the dark at $4^{\circ} \mathrm{C}$ until analysis. Negative control samples were incubated with isotype-matched control immunoglobulins instead of monoclonal antibodies.

\subsection{Quantification and image acquisition} Once sections were stained and dried, slides were attached onto the custom-modified slide holder developed for imaging on the Cellomics ${ }^{\circledR}$ Kineticscan reader. Three-colour image sets were acquired at 40x dry lens magnification. Quantitative data from stored digital images of the enterocytes were processed using the morphology explorer bioapplication tool Cellomics ${ }^{\circledR}$. This bioapplication was optimized for cell morphology analysis, including cytoskeletal rearrangements and Hoechst-stained nuclei. "Virtual" scans were carried out using specific assay parameters of fluorescent images of the enterocytes in each histological section. These were acquired and analyzed by proprietary image processing algorithms.

\subsection{Optimization of image acquisition}

The morphology explorer bioapplication was originally designed as a general tool that can perform a wide range of measurements related to cell morphology. The features and capabilities provide researchers with the flexibility to design their own assays. However, to date, this bioapplication has only been used to analyse cell lines. In this study, a new application was developed to allow examination of paraffin-embedded duodenal sections, so that individual cells within selected tissue areas could be analyzed in situ. A methodology was devised so that a 96 well plate could be used as a slide holder, with a system for identifying the duodenal tissue 


\begin{tabular}{|c|c|c|c|c|c|}
\hline Measurements & $\begin{array}{l}\text { Normal control } \\
\text { (non-coeliac) group }\end{array}$ & UTCD group & $T C D$ group & $\begin{array}{l}\text { SGS } \\
\text { (first D2 biopsies) }\end{array}$ & $\begin{array}{l}\text { SGS } \\
\text { (second D2 biopsies) }\end{array}$ \\
\hline Enterocyte length & 67 pixels (65- 74) & 53 pixels (47-59) & 56 pixels (65-74) & 57 pixels $(47-67)$ & 57 pixels (49-65) \\
\hline Enterocyte width & 11 pixels $(10-12)$ & 13 pixels $(11-14)$ & 12 pixels $(11-13)$ & 11 pixels $(9-12)$ & 14 pixels (13-16) \\
\hline $\begin{array}{l}\text { Enterocyte tubulin } \\
\text { fibre angles degree }\end{array}$ & $8.6(7.8-9.4)$ & $7.2(6.5-7.8)$ & $8.3(7-9.7)$ & $6.6(5.3-8)$ & $6.4(5.2-7.5)$ \\
\hline $\begin{array}{l}\text { Enterocyte tubulin } \\
\text { fibre staining } \\
\text { intensity }\end{array}$ & 174 pixels (124-220) & 330 pixels (249-411) & 230 pixels (150-310) & 290 pixels (161-419) & 373 pixels (201-545) \\
\hline $\begin{array}{l}\text { Enterocyte tubulin } \\
\text { fibre density }\end{array}$ & 48 pixels $(43-54)$ & 64 pixels (59-69) & 59 pixels (49-68) & 65 pixels $(52-77)$ & 66 pixels (54-78) \\
\hline $\begin{array}{l}\text { Enterocyte nuclear } \\
\text { shape (roundness) }\end{array}$ & 1.59 pixels (1.54-1.64) & 1.28 pixels (1.25-1.31) & 1.50 pixels (1.45-1.55) & 1.38 pixels (1.27-1.48) & 1.25 pixels (1.15-1.35) \\
\hline $\begin{array}{l}\text { Enterocyte nuclear } \\
\text { length width ratio }\end{array}$ & 2.06 pixels $(1.92-2.20)$ & 1.48 pixels $(1.42-1.53)$ & 1.87 pixels $(1.73-2.00)$ & 1.78 pixels $(1.61-1.93)$ & 1.54 pixels $(1.38-1.68)$ \\
\hline
\end{tabular}

Table 3. Characteristics of enterocyte morphology and tubulin profiles in the patient groups.

UTCD: untreated coeliac disease patients; TCD: treated coeliac disease patients; SGS: study group subjects. Results are expressed as mean and $95 \%$ confidence intervals.

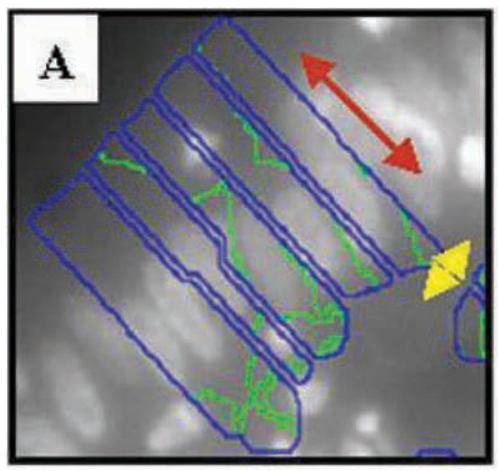

Normal control

(non-coeliac)

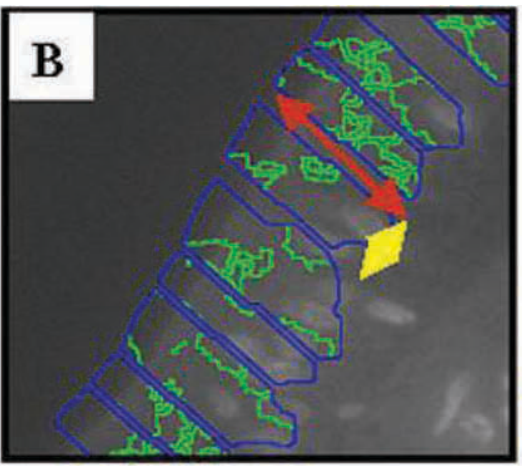

Untreated coeliac disease

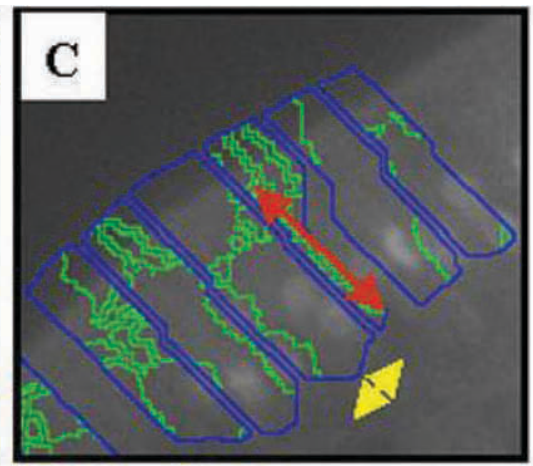

Study group subject (first D2 biopsy)

Figure 2. Algorithmic created images representing enterocyte length and width in small intestinal mucosa in the normal control group (noncoeliac) (A), Untreated coeliac disease (B) and in the study group subjects (first biopsy) (C). Red arrow represents the enterocyte length and yellow arrow represents their width. (magnification $\times 40$ ). The enterocyte length and width was measured based on the tubulin fibre staining using the optimized bioapplication tools.

region of interest (middle third of the villi) using a field map.

To examine enterocytes individually (Figure 2), we used three different fluorescent channels, each determining a specific morphological feature of the enterocyte. Furthermore, we set up parameters to examine whole cells and cytoskeletal fibre arrangement. These parameters (background correction, smooth factor in channel 1 and 2, object segmentation in channel 1 and 2, fibre detection and fibre alignment in channel 3) were activated simultaneously. Thus, we were able to measure the cell length, width, nuclear shape and the tubulin fibre profiles in each individual enterocyte from the duodenal sections. In some instances, enterocytes appeared to overlay each other; however, using the morphology explorer bioapplication tools it was possible to ensure that the measurement of only single cells was calculated.

\subsection{Statistical analysis}

The $95 \%$ confidence intervals $(\mathrm{Cl})$ of the enterocyte's structure characterization and the tubulin fibre profiles for all four patient groups were calculated. The MannWhitney $U$ test was then used to assess the statistical significance of differences. A $P$-value of $<0.05$ was considered to be statistically significant.

\section{Results}

The approximate measurements of the enterocyte shape were calculated based on the output features from the algorithmic image of the gross pattern of tubulin staining [28]. In each biopsy, a minimum of ten enterocytes were examined. The mean and $95 \% \mathrm{Cl}$ of enterocyte measurements and the tubulin fibre profiles 
(A) Enterocyte length

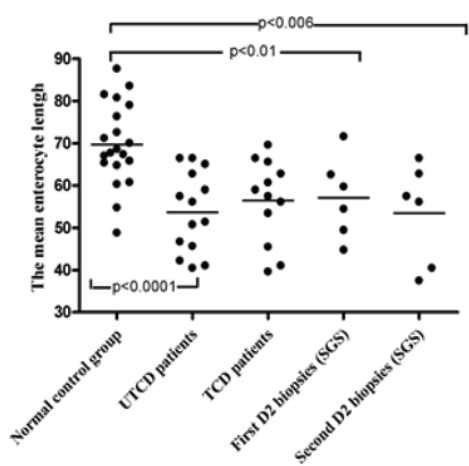

(C) Enterocyte tubulin fibre angles

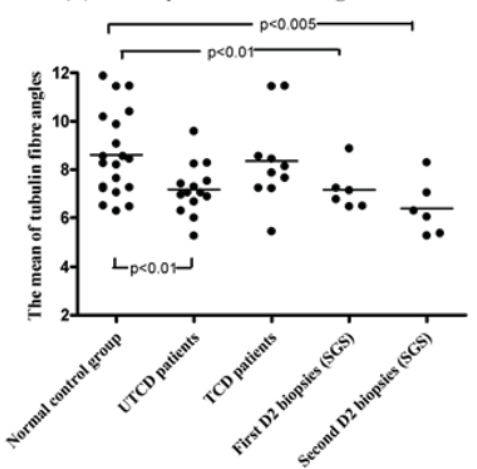

(E) Enterocyte tubulin fibre density

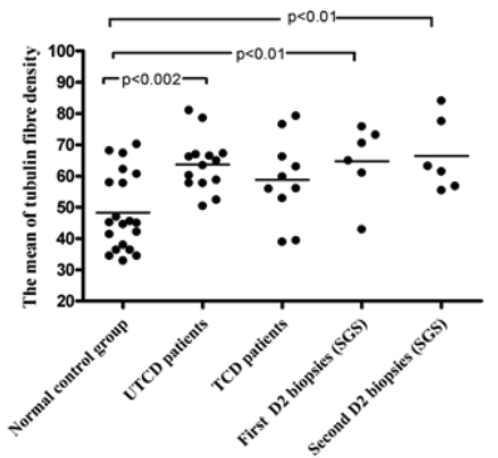

(G) Nuclear LWR

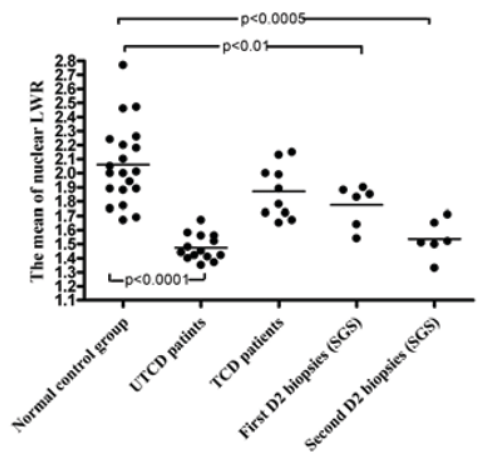

(B) Enterocyte width

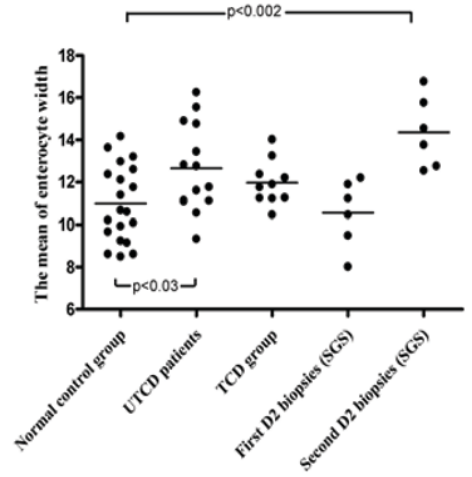

(D) Enterocyte tubulin fibre staining intensity

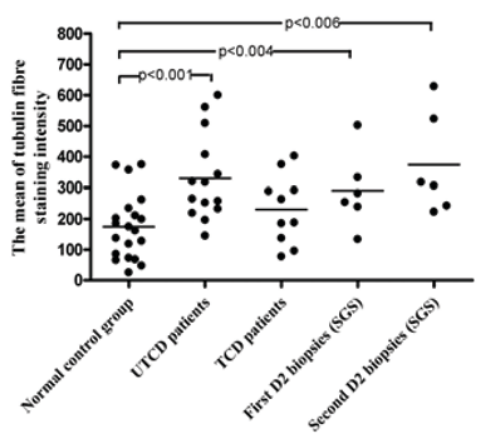

(F) Nuclear shape (roundness)

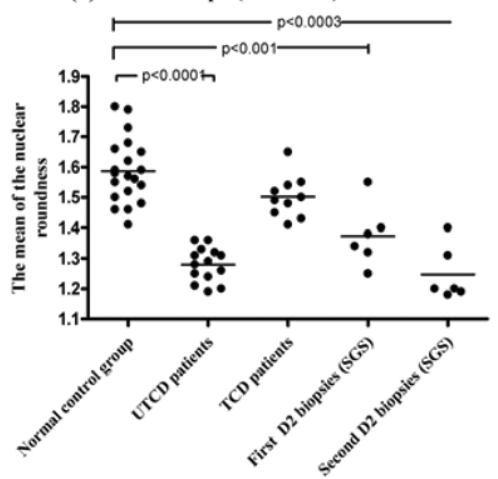

Figure 3. Quantification data of enterocyte morphology and tubulin structures in the normal control (non-coeliac) group, untreated coeliac disease patients (UTCD), treated coeliac disease patients (TCD) and in the study group subjects (SGS) (first and second duodenal biopsies). (magnification $\times 40$ ). Differences between the groups were calculated using the Mann-Whitney $U$ test. 
are summarized in Table 3. Results are expressed as the mean and range in pixels. Likewise, details of nuclear data are summarized in Table 3.

\subsection{Enterocyte length}

The enterocyte length was measured along the medial axis of the cells. In biopsy tissue from normal (noncoeliac) subjects, the mean enterocyte length was 67 pixels (range 65-74; Figure 2A). The enterocyte length was significantly reduced in all the patient groups (Figure $3 \mathrm{~A}$ ): in the untreated coeliac patients (mean 53 pixels, $p<0.000$; Figure 2B), in treated coeliac patients (mean 56 pixels, $p<0.001$ ) in the first biopsy of the study group subjects (mean 57 pixels $p<0.01$; Figure 2C) and in the second biopsy in the study group subjects (mean 57 pixels, $p<0.006$ ). Of note, the results were not statistically different within the all patient groups.

\subsection{Enterocyte width}

Enterocyte width was measured perpendicular to the middle axis of the cell. In the normal (non-coeliac) subjects, the mean enterocyte width was 11 pixels (range 9-12; Figure 2A). This was significantly lower than that found in the untreated coeliac patients (mean 14 pixels, $\mathrm{p}<0.002$; Figure 2B) and the second biopsy in the study group subjects (mean 13 pixels, $p<0.03$; Figure 2C). Interestingly, the enterocyte width in the treated coeliac patients and in the initial biopsy of the study group subjects was similar to the non-coeliac control subjects (Figure 3B).

\subsection{Enterocyte tubulin fibre angles}

Fibre angle measurement represents the degree of intracellular branching of tubulin. These measurements were performed based on the algorithmic referenced angles. Normal cells containing radially oriented fibres, such as tubulin fibres radiating from the cell center, have large degree angles. This is what was found in the normal (non-coeliac) columnar epithelial cells, which displayed a high tubulin angle degree (mean 8.6: range 7.8-9.4). Enterocyte tubulin fibre angles were significantly reduced in all the patient groups, except in the treated coeliac patients (Figure $3 \mathrm{C}$ ); in the untreated coeliac patients, the mean angle degree was $7.2(p<0.010)$; in first biopsy of the study group subjects, mean $6.6(p<0.01)$; in the second biopsy of the study group subjects, mean 6.4 $(p<0.005)$. Furthermore, the treated coeliac patients showed a significantly higher angle degree, mean 8.3, than the untreated coeliac patients $(p<0.04)$ and the second biopsies in the study group subjects $(p<0.02)$.

\subsection{Enterocyte tubulin fibre staining intensity}

In the tissue from normal (non-coeliac) subjects, the mean intensity of enterocyte tubulin fibre staining was 174 pixels (range124-220). Staining intensity was significantly greater in all the patient groups except in the treated coeliac patients (Figure 3D): in the untreated coeliac patients, the mean intensity was 330 pixels $(p<0.001)$; in the first biopsy in the study group, the mean intensity was 290 pixels $(p<0.04)$; in the second biopsy in the study group, the mean intensity was 373 pixels $(p<0.006)$. Within these three patient groups, no significant difference in the level of staining intensity was found (Table 3). The treated coeliac group, on the other hand, did not show any difference in comparison to the normal (non-coeliac) control group.

\subsection{Enterocyte tubulin fibre density}

The surface area density is a texture measurement which takes into account both the intensity variation and spatial distribution of the pixels within the enterocytes. In enterocytes from normal (non-coeliac) subjects, the mean tubulin fibre density was 48 pixels (range 4354). Enterocyte tubulin fibre density was significantly increased in all the patient groups, with the exception of treated coeliac patients (Table 3 ): in the untreated coeliac patients, the mean density value was 64 pixels $(p<0.001)$; in the first biopsy of the study group, the mean density was 65 pixels $(p<0.01)$; and in the second biopsy of the study group subjects, the mean density was 66 pixels $(p<0.01$; Figure $3 E)$.

\subsection{Nuclear shape (roundness)}

In the normal enterocyte, the nucleus has an elliptical shape. The measurement of the nuclear shape is based on the perimeter square area of the nucleus $\left(P^{2} A\right)$. $A$ higher nuclear $P^{2} A$ value is found in the nucleus of normal columnar epithelial cells, reflecting their elliptical shape. As the nuclear shape develops a more rounded shape, the closer the $\mathrm{P}^{2} \mathrm{~A}$ unit gets to a value of 1 . This feature was investigated in this study in the normal (noncoeliac) subjects and the patient groups (Figure 3F). In the biopsies from non-coeliac subjects, the mean $P^{2} A$ value was 1.59 pixels (range 1.54-1.64; Figure 4A). The $P^{2} A$ values were significantly closer to one in all the patient groups, in comparison to the non-coeliac subjects (Figure 4A); in the untreated patients, mean 1.28 pixels $(p<0.0001$; Figure $4 B)$; in the treated coeliac patients mean 1.50 pixels $(p<0.0001)$; in the first biopsy of the study group subjects mean 1.38 pixels $(p<0.001$; Figure 4C); and in the second biopsy of the study group subjects mean 1.25 pixels $(p<0.0003)$. Of interest, the nuclear $\mathrm{P}^{2} \mathrm{~A}$ values in the treated coeliac patients were 


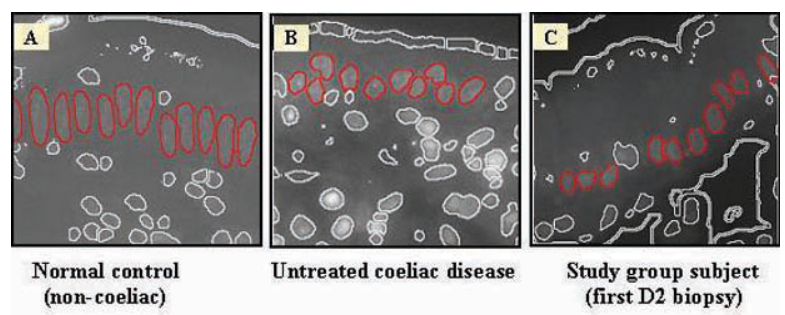

Figure 4. Algorithmic created images representing enterocyte nuclei (red) in small intestinal mucosa in the normal control group (non-coeliac) (A), Untreated coeliac disease (B) and in the study group subjects (first biopsy) (C).

significantly greater than the untreated coeliac patients $(p<0.001)$, than the first biopsy of the study group subjects $(p<0.01)$ and than the second biopsy in the study group subjects $(p<0.0002)$.

\subsection{Nuclear length and width ratio (LWR)}

The enterocyte nuclear length and width ratio (LWR) was also examined based on the $\mathrm{P}^{2} \mathrm{~A}$. A high nuclear LWR value is found in the nucleus of normal columnar epithelial cells and in the biopsy tissue from the normal (non-coeliac) subjects (Figure 3G), the mean nuclear LWR was 2.01 pixels (range 1.92-2.20). In comparison with the non-coeliac subjects, the nuclear LWR was significantly reduced in the untreated coeliac patients, mean 1.47 pixels $(p<0.0001)$; in the first biopsy of the study group, mean 1.78 pixels $(p<0.01)$; and in the second biopsy in the study group, mean 1.54 pixels $(p<0.0005)$. In the treated coeliac patients, nuclear LWR was not significantly different from the non-coeliac subjects.

\section{Discussion}

This is the first study to examine enterocyte morphology in histological tissue sections using digitalized high content analysis. This technology, in combination with a bioapplication software package named morphology explorer, was used to accurately quantify enterocyte length and width, nuclear shape and both tubulin fibre alignment and texture. Duodenal biopsy tissue from patients with coeliac disease and from noncoeliac control subjects was examined. In addition, histological sections from a group of patients with a positive endomysial antibody test - before and after the development of an observable duodenal histological lesions (designated the "study group subjects") - were investigated. When these study group subjects were originally investigated, no histological lesion was noted, although this might have been due to the presence of patchy disease [4-6] or when subtle abnormalities, only detectable by immunohistochemistry, were present [30]. Significant differences in enterocyte morphology and intracellular structures were demonstrated in all the patient groups in comparison to the control subjects.

High content analysis was originally designed to study cells in suspension [31-33] and there are no previous reports of employing this technology to examine cells in fixed tissue sections. In this study, we were able to modify the technology and demonstrate a new application for this system: This allowed detailed analysis of cell morphology and intracellular cytoskeletal structures of individual cells in tissue sections. This is a considerable advance on computer aided image analysis which, although helpful in tissue analysis, does not allow for similar detailed examination of individual cells $[34,35]$.

A decrease in epithelial cell height and increase in cell width are commonly described features of enterocytes in coeliac disease [7]. Using high content analysis, a statistically significant reduction in enterocyte length (or height) was found in both untreated and treated coeliac patient groups. Of interest, a similar reduction in length was also evident in the study group subjects in both sets of samples i.e. before an apparent histological lesion and after the development of a lesion. In the case of enterocyte width, a significant increase in width was only present in the untreated coeliac patients and in the second set of biopsies from the study group.

The shape of cell nuclei was a further morphological feature, which was investigated in these biopsies. Earlier studies employing high content analysis have reported that the cell nucleus is a valid object for morphological quantification [31-33]. In contrast to the elliptical shape found in normal enterocytes, in coeliac disease cell nuclei tend to have a more rounded appearance [7]. Using the analytical system described here, this observation was confirmed and it was demonstrated that a significant shape alteration was found not only in the coeliac biopsy tissue but also in both sets of biopsies from the study group subjects. Based on this finding, changes in nuclear shape appear to act as evidence of the development of a coeliac lesion.

Tubulin is the major component of the microtubules and with other cytoskeletal proteins forms the essential structural framework of cells [12-36]. In this study, enterocyte tubulin fibre parameters were analyzed, including tubulin fibre angles, fibre staining intensity and fibre density. Alteration of all these parameters was found in the untreated coeliac patients and similar significant alterations were observed in the initial and repeat biopsies in the study group subjects. Interestingly, significant changes were not observed in the treated coeliac patient biopsies. 
The re-arrangement of intracellular tubulin may be responsible for the alteration in enterocyte morphology in the coeliac and study group subjects. This may explain why these cells lose their columnar shape. It is also possible that these changes may affect the cell:cell adherence of intestinal epithelial cells, a well described finding in coeliac disease [37-40]. The continuity of the surface epithelium is maintained by tight junctions (zona occulens) and by actin-rich connections (zona adherens and zona maculens), which join the uppermost portions of the cells. Tubulin is required for maintaining tight junction adherence and this may occur via regulation of F-actin [41]. Of interest, actin is a target of $\lg A$ autoantibodies in coeliac disease and the level of these antibodies was found to correlate with the extent of intestinal damage [42-43]. It has also been reported that $\lg$ A anti-actin antibodies could possibly be used to detect coeliac patients when they present with only patchy intestinal lesions [44]. Recent studies in our laboratory have revealed that smooth muscle alpha-actin may be the principal antigenic target of these antibodies ( $\mathrm{J}$. Dunne, personal communication).

Taken together, the results presented here suggest that high content analysis is able to accurately detect subtle morphological alterations in enterocytes, even in patients with apparently normal histology on routine microscopic examination. Thus, these changes may be very early features of gut inflammation and it was noteworthy that they were observed in the first duodenal biopsy of the study group subjects. It was also of interest

\section{References}

[1] Cooke W.T., Holmes G.K.T., Coeliac disease, Churchill Livingstone, London, 1984

[2] Marsh M.N., Mucosal pathology in gluten sensitivity, In: Marsh M.N. (Ed.), Coeliac disease, Blackwell Scientific, Oxford, 1992, 136-191

[3] Trier J.S., Diagnosis of celiac sprue, Gastroenterology, 1998, 115, 211-216

[4] Kaukinen K., Maki M., Partanen J., Sievanen H., Collin P., Celiac disease without villous atrophy: revision of criteria called for, Dig. Dis. Sci., 2001, 46, 879-887

[5] Mino M., Lauwers G.Y., Role of Iymphocytic immunophenotyping in the diagnosis of gluten-sensitive enteropathy with preserved villous architecture, Am. J. Surg. Pathol., 2003, 27, 1237-1242

[6] Settakorn J., Leong A.S., Immunohistologic parameters in minimal morphologic change duodenal biopsies from patients with clinically suspected glutensensitive enteropathy, Appl. Immunohistochem. Mol. Morphol., 2004, 12, 198-204

[7] Magliocca F.M., Bonamico M., Petrozza V., Correr S., that the alterations were not more pronounced after a clear cut histological lesion had developed. These findings are of value in understanding the pathogenesis of coeliac disease and may point to a direct damaging effect on enterocytes caused by gluten. It is also important to note that enterocytes play a direct role in the immune response and have been shown to produce cytokines such as IL-6, IL-8 and IL-15 in response to injury or infection, thereby affecting the function of other immunocompetent cells [45].

In summary, this study demonstrates the value of digitalized high content analysis of tissue sections in coeliac disease. This novel technology could be employed to identify patients with early onset gluten sensitive enteropathy and could also help dissect pathogenic events in coeliac disease at the sub-cellular level.

\section{Acknowledgements}

During this study, B. Mohamed was supported by a grant from the Ministry of Scientific Research, Libya. The authors would like to thank Ms Katrina Drayton (Cellomics; European group), Dr. J. Jackson and Ms. Caroline Liddy for technical and scientific support. We would also like to acknowledge the Department of Histopathology, St. James's Hospital, Dublin, Ireland.

Montuori M., Triglione P., Scanning electron microscopy of the small intestine during gluten-challenge in celiac disease, Arch. Histol. Cytol., 1992, 55, 125-130

[8] Jarvinen T.T., Collin P., Rasmussen M., Kyronpalo S., Maki M., Partanen J., Villous tip intraepithelial lymphocytes as markers of early-stage coeliac disease, Scand. J. Gastroenterol., 2004, 39, 428-433

[9] Biagi F., Luinetti O., Campanella J., Klersy C., Zambelli C., Villanacci V., Intraepithelial lymphocytes in the villous tip: do they indicate potential coeliac disease?, J. Clin. Pathol., 2004, 57, 835-839

[10] Fuchs E., Cleveland D.W., A structural scaffolding of intermediate filaments in health and disease, Science, 1998, 279, 514-519

[11] Banan A., Choudhary S., Zhang Y., Fields J.Z., Keshavarzian A., Ethanol-induced barrier dysfunction and its prevention by growth factors in human intestinal monolayers: evidence for oxidative and cytoskeletal mechanisms, J. Pharmacol. Exp. Ther., 1999, 291, 1075-1085 
[12] Fenteany G., Glogauer M., Cytoskeletal remodeling in leukocyte function, Curr. Opin. Hematol., 2004, $11,15-24$

[13] Banan A., Smith G.S., Rickenberg C., Kokoska E.R., Miller T.A., Protection against ethanol injury by prostaglandin in a human intestinal cell line: role of microtubules, Am. J. Physiol. Gastrointest. Liver Physiol., 1998, 274, G111-G121

[14] Banan A., Smith G.S., Deshpande Y., Rieckenberg C.L., Kokoska E.R., Miller TA., Prostaglandins protect human intestinal cells against ethanol injury by stabilizing microtubules: Role of protein kinase C and enhanced calcium efflux, Dig. Dis. Sci., 1999, 44, 697-707

[15] Banan A., Choudhary S., Zhang Y., Fields J.Z., Keshavarzian A., Oxidant-induced intestinal barrier function disruption and its prevention by growth factors in a human colonic cell line: role of the microtubule cytoskeleton, Free Radic. Biol. Med., 2000, 28, 727-738

[16] Lane E.B., McLean W.H., Keratins and skin disorders, J, Pathol., 2004, 204, 355-366

[17] Zatloukal K., Stumptner C., Fuchsbichler A., Fickert P., Lackner C., Trauner M., The keratin cytoskeleton in liver diseases, J. Pathol., 2004, 204, 367376

[18] Chaponnier C., Gabbiani G., Pathological situations characterized by altered actin isoform expression, J. Pathol., 2004, 204, 386-395

[19] Rottner K., Lommel S., Wehland J., Stradal T.E., Pathogen-induced actin filament rearrangement in infectious diseases, J. Pathol., 2004, 204, 396406

[20] Cairns N.J., Lee V.M., Trojanowski J.Q., The cytoskeleton in neurodegenerative diseases, J. Pathol., 2004, 204, 438-449

[21] Banan A., McCormack S.A., Johnson L.R., Polyamines are required for microtubule formation during gastric mucosal healing, Am. J. Physiol. Gastrointest. Liver Physiol., 1998, 274, G879-G885

[22] Oberhuber G., Granditsch G., Vogelsang H., The histopathology of coeliac disease: time for a standardized report scheme for pathologists, Eur. J. Gastroenterol. Hepatol., 1999, 11, 1185-1194

[23] Oxentenko A.S., Grisolano S.W., Murray J.A., Burgart L.J., Dierkhising R.A., Alexander J.A., The insensitivity of endoscopic markers in celiac disease, Am. J. Gastroenterol., 2002, 97, 933-938

[24] Holmgren P.K., Magnusson K.E., Stenhammar L., Falth-Magnusson K., Confocal laser scanning microscopy of small-intestinal mucosa in celiac disease, Scand. J. Gastroenterol., 1995, 30, 228-234

[25] Bailey D.S., Freedman A.R., Price S.C., Chescoe
D., Ciclitira P.J., Early biochemical responses of the small intestine of coeliac patients to wheat gluten, Gut, 1989, 30, 78-85

[26] Clemente M.G., De Virgiliis S., Kang J.S., Macatagney R., Musu M.P., Di Pierro M.R., Early effects of gliadin on enterocyte intracellular signalling involved in intestinal barrier function, Gut, 2003, 52, 218-223

[27] Pizzuti D., Bortolami M., Mazzon E., Buda A., Guariso G., D'Odorico A., et al., Transcriptional downregulation of tight junction protein $\mathrm{ZO}-1$ in active coeliac disease is reversed after a gluten-free diet, Dig. Liver Dis., 2004, 36, 337-341

[28] Hong S.J., Keefer S., Ghosh R.N., Simultaneous quantitative monitoring of cytoskeletal rearrangement and changes in cell morphology, Nat. Meth. Appl. Notes, 2007, 15-17

[29] Oberhuber G., Granditsch G., Vogelsang H., The histopathology of coeliac disease: time for a standardized report scheme for pathologists, Eur. J. Gastroenterol. Hepatol., 1999, 11, 1185-1194

[30] Mohamed B. M., Feighery C., Coates C., O'Shea U., Delaney D., O'Briain S., The absence of a mucosal lesion on standard histological examination does not exclude diagnosis of celiac disease, Dig. Dis. Sci., 2008, 53, 52-61

[31] Ghosh R.N., Grove L., Lapets O., A quantitative cellbased high-content screening assay for the epidermal growth factor receptor-specific activation of mitogen-activated protein kinase, Assay Drug Dev. Technol., 2004, 2, 473-481

[32] Abraham V.C., Taylor D.L., Haskins J.R., High content screening applied to large-scale cell biology, Trends Biotechnol., 2004, 22, 15-22

[33] Bland P.W., MHC class II expression by the gut epithelium, Immunology Today, 1988, 9, 174-178

[34] Slavin G., Sowter C., Robertson K., McDermott S., Paton K., Measurement in jejunal biopsies by computer-aided microscopy, J. Clin. Pathol., 1980, 33, 254-261

[35] Corazza G.R., Frazzoni M., Dixon M.F., Gasbarrini G., Quantitative assessment of the mucosal architecture of jejunal biopsy specimens: a comparison between linear measurement, stereology, and computer aided microscopy, J. Clin. Pathol., 1985, $38,765-770$

[36] MacRae T.H., Towards an understanding of microtubule function and cell organization: an overview, Biochem. Cell Biol., 1992, 70, 835-841

[37] Schulzke J.D., Bentzel C.J., Schulzke I., Riecken E.O., Fromm M., Epithelial tight junction structure in the jejunum of children with acute and treated celiac sprue, Pediatr. Res., 1998, 43, 435-441 
[38] Bjarnason I., Maxton D., Reynolds A.P., Catt S., Peters T.J., Menzies I.S., Comparison of four markers of intestinal permeability in control subjects and patients with coeliac disease, Scand. J. Gastroenterol., 1994, 29, 630-639

[39] Friis S., Dabelsteen E., Sjostrom H., Noren O., Jarnum S., Gliadin uptake in human enterocytes. Differences between coeliac patients in remission and control individuals, Gut, 1992, 33, 1487-1492

[40] Montalto M., Cuoco L., Ricci R., Maggiano N., Vecchio F.M., Gasbarrini G., Immunohistochemical analysis of ZO-1 in the duodenal mucosa of patients with untreated and treated celiac disease, Digestion, 2002, 65, 227-233

[41] Waterman-Storer C.M., Salmon W.C., Salmon E.D., Feedback interactions between cell-cell adherens junctions and cytoskeletal dynamics in newt lung epithelial cells, Mol. Biol. Cell., 2000, 11, 24712483
[42] Clemente M.G., Musu M.P., Frau F., Brusco G., Sole G., Corazza G.R., et al., Immune reaction against the cytoskeleton in coeliac disease, Gut, 2000, 47, 520-526

[43] Granito A., Muratori P., Cassani F., Pappas G., Muratori L., Agostinelli D., et al., Anti-actin IgA antibodies in severe coeliac disease, Clin. Exp. Immunol., 2004, 137, 386-392

[44] Clemente M.G., Musu M.P., Troncone R., Volta U., Congia M., Ciacci C., et al., Enterocyte actin autoantibody detection: a new diagnostic tool in celiac disease diagnosis: results of a multicenter study, Am. J. Gastroenterol., 2004, 99, 1551-1556

[45] Stadnyk A.W., Cytokine production by epithelial cells, FASEB J., 1994, 8, 1041-1047 